\title{
Does knowledge management really matter? Linking knowledge management practices, competitiveness and economic performance
}

\author{
Tatiana Andreeva and Aino Kianto
}
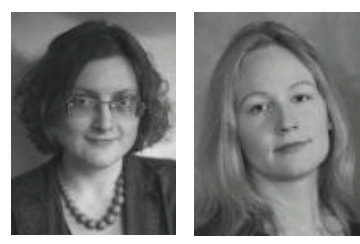

Tatiana Andreeva is Associate Professor in the Department of Organizational Behavior and Human Resource, St Petersburg University Graduate School of Management, St Petersburg, Russia. Aino Kianto is Professor in the School of Business, Lappeenranta University of Technology, Lappeenranta, Finland.
Received: November 2011 Revised: January 2012 February 2012 Accepted: March 2012 The authors would like to express their gratitude to MSc Henri Inkinen, MSc Yaroslav Pavlov and MSc Xing Shi for their research assistance.

\begin{abstract}
Purpose - While nowadays an extensive literature promoting knowledge management (KM) exists, there is a worrying shortage of empirical studies demonstrating an actual connection between KM activities and organizational outcomes. To bridge this gap, this paper aims to examine the link between KM practices, firm competitiveness and economic performance.

Design/methodology/approach - This paper proposes a framework of KM practices consisting of human resource management (HRM) and information communication technology (ICT). These both are hypothesized to impact competitiveness and economic performance of the firm. Hypotheses are then tested with structural equation modeling by using a survey dataset of 234 companies.

Findings - The results show that HRM and ICT practices for managing knowledge are quite strongly correlated and have a statistically significant influence on both financial performance and competitiveness of the firm. The findings also indicate that ICT practices improve financial performance only when they are coupled with HRM practices.
\end{abstract}

Research limitations/implications - The data are limited to companies from Finland, Russia and China.

Practical implications - The paper contributes to managerial practice by pointing out the importance of utilizing a combination of both social and technical means for KM and illustrating that they do matter for the company bottom line.

Originality/value - This paper contributes to the literature on knowledge-based organizing by empirically analyzing the performance impact of various areas of KM. It thereby tests the proposition put forth in many previous theoretical and case-based studies that KM promotes high organizational performance. It also addresses the interaction of social and technical KM practices in producing organizational outcomes.

Keywords Knowledge management, Knowledge management practices, Performance, Economic performance, Competitiveness, Socio-technical, Human resource management, Information communication technology, Communication technologies

Paper type Research paper

\section{Introduction}

It seems that knowledge management (KM), in terms of management philosophy, organizational activities, and technological methods, has widely permeated the business world. The main reason for the wide-spread penetration of $\mathrm{KM}$ in managerial rhetoric and practice is, of course, the underlying assumption that management of knowledge somehow makes a difference to the company bottom line. However, when examining the existing academic literature on the topic, one cannot fail to notice the relative shortage of empirical studies demonstrating an actual connection between KM and organizational performance. Without clearly demonstrated benefits, why should companies keep on investing in KM? As Demarest (1997, p. 381) notes: 
If knowledge management does not support the objective of increasing the quality and quantity of market-place performance, it is at best a soft discipline - useful for enhancing corporate culture, but finally a nice-to-have, rather than a necessary practice.

Indeed, for a long time, literature addressing the KM-performance link consisted of theoretical papers proposing hypothetical relationships between aspects of $\mathrm{KM}$ and organizational outcomes (Carneiro, 2000; Adams and Lamont, 2003; Chapman and Magnusson, 2006), and case studies of highly successful KM applications (Nonaka and Takeuchi, 1995; Edvinsson and Malone, 1997; Zaim et al., 2007). The situation has changed recently, as studies empirically assessing the impact of $\mathrm{KM}$ on performance in larger samples of firms have appeared (Lee and Choi, 2003; Gloet and Terziovski, 2004; Marqués and Simón, 2006; Darroch, 2005; Tanriverdi, 2005; Zack et al., 2009; Kianto, 2011). The overall conclusion derived from these studies is that $\mathrm{KM}$ has some impact on performance, although there is some disagreement as to whether this impact is direct or mediated by some other variables, such as organizational processes or intermediate performance indicators.

Despite the growing evidence of KM's contribution to organizational performance, there are several issues that still have not been fully addressed in the existing studies. First, performance has been interpreted and measured very differently across existing studies, ranging from innovativeness (Darroch and McNaughton, 2003; Gloet and Terziovski, 2004; Kiessling et al., 2009; Kianto, 2011) and product and employee improvement (Kiessling et al., 2009) to product leadership, customer intimacy and operational excellence (Zack et al., 2009) and competitive position (Lee and Choi, 2003). Only few studies have addressed financial outcomes (Tanriverdi, 2005; Darroch, 2005; Marqués and Simón, 2006; Zack et al., 2009).

Second, most of the studies focus on knowledge processes rather than on knowledge management practices. Though knowledge processes can be stimulated or inhibited by particular management practices, they also naturally exist in any organization irrespectively of managerial efforts (Demarest, 1997; Husted and Michailova, 2002). Therefore, studies that only focus on knowledge processes cannot inform managers about solutions that can improve their firm's performance through better management of knowledge. In line with this argument, the emerging knowledge governance approach highlights the lack of studies of formal organization from KM perspective and calls for more research in this field (Foss et al., 2010). Making the proper interpretation of their findings even more problematic, a number of studies mix knowledge processes and management practices within their variables (e.g. Darroch, 2005; Zack et al., 2009).

Third, there is a lack of studies examining the interrelations of several KM practices in their contribution to organizational performance. Indeed, Foss et al. (2010) argue that the ways in which formal governance mechanisms may interact in influencing outcomes of knowledge processes have been under-researched.

This study addresses these gaps and examines how KM practices impact firms' competitiveness and financial performance. Knowledge management practices are distinguished from knowledge processes, and the focus of the paper is on the former. KM practices refer to the aspects of the organization that are manipulable and controllable by conscious and intentional management activities. Accordingly, KM is conceptualized as the set of management activities that enable the firm to deliver value from its knowledge assets.

Based on the KM literature that discusses social and technical aspects of organizing as the main KM elements,

In the literature, $\mathrm{KM}$ is often presented as a combination of both technical and human aspects. Therefore the paper focuses on two groups of management practices that are shaped based on managerial decisions and can impact effectiveness of KM - human resource management (HRM) and information and communication technologies (ICT). The impact of these practices on the perceived competitiveness and financial performance of companies is empirically examined. Also the interaction of the KM practices in producing the performance outcomes is investigated.

PAGE 618 | JOURNAL OF KNOWLEDGE MANAGEMENT | VOL. 16 NO. 42012 
The paper is organized as follows: it begins by introducing conceptual and empirical grounds of the impact of knowledge management practices on performance. Next, existing research on HRM and ICT practices aimed to support KM and their influence on performance is reviewed and hypotheses and research model are formulated. Then research methodology is discussed, followed by findings and their discussion. The paper concludes with managerial implications, research limitations, and avenues for further investigation.

\section{Theoretical background}

\subsection{The contribution of knowledge management to organizational performance}

The relevance of knowledge and its effective and efficient management for organizational performance seems to be a widely accepted issue in most of current management literature.

The key literatures addressing the role of knowledge and its management in organizational performance are the resource-based view of the firm (e.g. Penrose, 1959; Barney, 1991) and the knowledge-based view of the firm (Kogut and Zander, 1992; Grant, 1996; Spender, 1996). Both of these take as their starting point the core assumption that competitiveness of the firm does not so much depend on its product-market positioning in relation to external competitors, as on its internal characteristics.

According to the knowledge-based view, performance differences between organizations accrue due to their different stocks of knowledge and their differing capabilities in using and developing knowledge (e.g. Penrose, 1959; Kogut and Zander, 1992; Grant and Spender, 1996; Grant, 1996). Thus an important focus of the KBV is how knowledge resources are utilized and coordinated in organizations - i.e. Management of knowledge.

Knowledge management (KM) refers to identifying and leveraging the collective knowledge in an organization to help the organization compete (Von Krogh, 1998). From a practical perspective, KM can be seen as an organizational innovation involving changes in strategy and management practices of firms (Marqués and Simón, 2006). KM typically is seen to consist of knowledge processes (such as knowledge creation, sharing, acquisition, transfer and application) and infrastructures or capabilities or management activities that support and enhance the knowledge processes (e.g. Lee and Choi, 2003; Gold et al., 2001).

Accordingly, a distinction can be made between knowledge processes and knowledge management practices. The first refers to the knowledge processes that naturally exist in organization (e.g. knowledge sharing or knowledge acquisition), and latter ones to those management practices which support the efficient and effective management of knowledge for organizational benefit. Knowledge processes are out of direct managerial control and therefore their study portrays knowledge-based picture of an organization but does not explicitly inform organizational decision-makers about potential solutions to improve them. Thus a suitable working definition for the current paper is that KM consists of a set of management activities that enable the firm to deliver value from its knowledge assets.

While it is argued that KM can bring direct economic benefits to the firm through saving or earning money (e.g. Davenport et al., 1998), a more usual view seems to be that the impact on financial performance of the firm is indirect. For example, according to Demarest (1997), management of knowledge delivers economic benefits to the firm by such various manners as accelerating innovation and structural agility; reducing cycle time and program failures; creating a healthy and knowledge-friendly culture; attracting and maintaining high-quality knowledge workforce; and by improving re-use levels of knowledge and corporate memory. In empirical studies, KM has been shown to be connected with product leadership, customer intimacy and operational excellence (Zack et al., 2009); innovation (Darroch and McNaughton, 2003; Gloet and Terziovski, 2004; Darroch, 2005; Kianto, 2011; Andreeva and Kianto, 2011); organizational creativity (Lee and Choi, 2003); KM performance (Zaim et al., 2007); competitive advantage (Chuang, 2004); organizational effectiveness (Gold et al., 2001); firm's overall performance (Lee and Choi, 2003; Marqués and Simón, 2006; Darroch, 
2005); and also in some studies, directly with financial performance (Zack et al., 2009; Tanriverdi, 2005; Darroch and McNaughton, 2003).

Having now established the performance improving potential of $\mathrm{KM}$, the next sections move on to examine distinct KM practices and their performance impacts. Specifically, the focus is on two main elements of the managerial system comprising KM: management practices connected with ICT and HRM aimed to support effective and efficient management of knowledge for organizational benefit.

\subsection{KM practices for governing knowledge}

Discussing the knowledge-related literature of the recent decades, Foss et al. (2010) note that while there is a vast amount of writings concerning the characteristics of knowledge, knowledge taxonomies, how knowledge may be disseminated within and between organizations and the philosophical foundations of knowledge, there is a neglect of the formal organization. According to Foss (2007, p. 37), when organizational issues are discussed in relation to knowledge processes, "'organization' predominantly means 'informal organization', that is, networks, culture, communities of practice and the like, rather than formal governance mechanisms" (Foss, 2007, p. 37). He points out that formal organization may be invoked, but is "seldom if ever integrated into the analysis" and in general, "there is a neglect of formal organization".

A number of management scholars have recently proposed a novel perspective on knowledge in organizations, labeled the knowledge governance approach (Foss, 2007). The knowledge governance has as its starting point the assumption that "to realize the competitive potential of knowledge as a strategic resource, intra-organizational knowledge processes should be influenced and directed through the deployment of governance mechanisms, in particular the formal aspects of organization that can be manipulated by management" (Foss and Minbaeva, 2009, p. 16). Such formal aspects include, e.g. HRM, organizational structure, information systems, operating procedures and other coordination mechanisms. This approach focuses on the formal aspects of organizing and aims to understand the linkages between individual, team and organizational levels of analysis.

While the current paper does not fully embrace the knowledge governance approach, since it does not address the individual and team levels, it studies those aspects of organizing which are subject to conscious and intentional management control. So in the sense that knowledge governance relates with choosing structures and mechanisms that can influence knowledge processes in organizations (Foss and Michailova, 2009), the paper is inspired by this approach.

Taking the aspects of organization that are manipulable and controllable by conscious and intentional management activities as the starting point, it is proposed that conceptualize KM as a set of management activities that enable the firm to deliver value from its knowledge assets. These management activities can be called KM practices. KM practices are management practices aimed to support efficient and effective management of knowledge for organizational benefit.

Based on the existing literature on KM, there seem to be two main sets of such practices widely employed in companies: one related with information technology and computer-supported communication, and the other related with human resource management. For example according to Bhatt (2001) both technological and social systems are necessary in $\mathrm{KM}$ and it is the interaction between these that enables managing knowledge effectively. Also according to Hansen et al. (1999) the main KM practices are related with information technology and HRM (hiring, training, rewarding). Both of these figure in codification and personalization strategies, but with different foci. In codification strategy, information technology is heavily invested in and its goal is to connect people with reusable codified knowledge. People are rewarded for using and contributing to document databases. In personalization strategy, the goal of information technology is to facilitate conversations and exchange of tacit knowledge and people are rewarded for directly sharing knowledge with others. It should be noted that the current examination is not

PAGE $620 \mid$ JOURNAL OF KNOWLEDGE MANAGEMENT | VOL. 16 NO. 42012 
focused on every possible ICT or HRM practice but only those that are explicitly aimed to support knowledge processes in an organization. The following sections examine these practices in more detail.

\subsection{ICT practices for KM and performance}

Information and communication technologies are potent enablers of organizational knowledge processes and most of the knowledge-related literature argues that building appropriate ICT systems is an integral part of successful knowledge management. For example, Adams and Lamont (2003) argue that knowledge management systems i.e. Technological information systems composed of hardware, software and processes that organizations utilize to facilitate communication and information processing, are crucial in gaining and maintaining sustainable competitive advantage.

Analyzing the usage of ICT in organizational KM projects, Davenport et al. (1998) conclude that IT typically is applied for two main purposes. First, for creation of knowledge repositories which might include external knowledge such as competitive intelligence; structured internal knowledge (e.g. Research reports, marketing materials, techniques); and informal internal knowledge (e.g. lessons learned). Another typical application is improving knowledge access through creation of corporate knowledge directories (such as company yellow pages) and expert networks.

According to Alavi and Leidner (2001) knowledge management systems, by drawing on various and flexible ICT capabilities, can lead to various forms of KM support, extending beyond the traditional storage and retrieval of coded knowledge. They point out four major contributions of ICT: First, ICT supports knowledge creation by combining new sources of knowledge and by facilitating just-in-time learning through decreasing the time delay of knowledge sharing between organizational members. Second, ICT represents a major assistance for storage and retrieval of the organizational memory, as it acts as a platform for valuable knowledge that has been gained by the organization. Third, ICT assists knowledge sharing by providing more communication channels in the organization. Fourth, ICT also supports knowledge application by integrating knowledge into the organizational routines. In sum, the application of information technologies can create an infrastructure and environment that contribute to KM by augmenting and supporting a multitude of knowledge processes.

In her classical book "In the age of the smart machine: The future of work and power" Zuboff (1988) suggests three major impacts information technologies have for a firm's production processes: automation of processes, provision of better information and transforming entire processes. Automation allows information technology to substitute for human labor; improved information allows for more effective decision-making, and transformation impacts occur when a firm redesigns productive processes to achieve significantly higher levels of productivity (Dedrick et al., 2003). In addition to its role as a production technology, it has been argued that information technology has its greatest impact in the production process through enabling coordination of activity (Dedrick et al., 2003; Tanriverdi, 2005), thereby allowing for knowledge transfer and integration within and across organizational boundaries and organizational change.

Most of the empirical work on performance impact of ICT has been done in the information technology payoff literature (e.g. Barua et al., 1995; Brynjolfsson and Hitt, 1996; Devaraj and Kohli, 2003; Kohli and Devaraj, 2003; Dedrick et al., 2003) which examines the financial impact of information technology investments. While this literature has yielded contradictory findings on the performance impact of information technology investments, some recent critical reviews of the field have argued that also the actual usage of information technologies (Devaraj and Kohli, 2003) and their links with organizational complements such as managerial systems and strategies (Dedrick et al., 2003) should be taken into account. This points to that rather than examining the mere existence of ICT systems, or the amount of money spent on them, it is more important to examine the extent to which they actually are used for facilitating knowledge work processes and whether they fit with the strategic goals of the firm and are supported by requisite management practices. If these factors are taken 
into account, then a positive impact between ICT and organizational performance can be established. In connection with $\mathrm{KM}$, this points to the importance of considering not the mere existence of ICT but rather more specifically its potential for facilitating knowledge work processes. Some key aspects to consider when developing ICT for knowledge work are focusing on user's needs, building common and easy-to-use platforms, concentrating on both tacit and explicit knowledge management, giving enough training to users, and giving sustainable maintenance to ICT systems (Hasanali, 2002).

Even though ICTs have a widely accepted role as a crucial facilitator of knowledge work processes and organizational performance, empirical investigations other than case studies of the link between ICT for KM and performance have been rather scarce. In a survey of 250 US firms, Tanriverdi (2005) found that information technology-relatedness ("the use of common information technology infrastructures and common information technology management processes across business units") of a MNC increases its KM capability, which in turn positively impacts financial performance of the firm. Zaim et al. (2007) found that information technology improves KM performance. Gloet and Terziovski (2004) found that a KM model with an information technology focus on quality and productivity improves innovation performance. Lee and Choi (2003) studied the connections of KM enablers, knowledge creation processes, organizational creativity and performance. According to their results, information technology support only enhanced the combination phase of knowledge creation, but had no impact on other study variables. It can be concluded that there only have been few quantitative studies on the relations between ICTs for KM and performance and the results of those have not been fully supportive of the theoretical and case-study based claims of the role of the contribution of ICT to knowledge-based value creation. Thus there is a need for further empirical inspections on this issue.

Based on the previous theoretical discussion on ICT usage as a powerful tool for enabling capturing, storing and disseminating organization's knowledge assets, and related empirical proof from information technology payoff studies on their positive performance impact, it can be argued that the extent to which an organization's ICT systems support its knowledge work processes will increase its competitiveness and financial performance. ICT enables effective and efficient management of organizational knowledge, which in turn is a key competitive asset. There also exists proof that ICTs have a positive impact on economic performance of the firm. In line with the recent developments in the information technology payoff literature, it should be noted that what is important here is not the mere existence of ICT systems but their usability and usefulness for supporting daily work. Hence it is proposed that:

H1. The more an organization utilizes ICT practices for managing knowledge, the higher level of competitiveness it attains.

H2. ICT practices that support $\mathrm{KM}$ have a positive impact on the economic performance of the firm.

\subsection{HRM practices for KM and performance}

HRM is typically defined as the management of the organization's employees (Foot and Hook, 2008). Usually HRM functions include tasks such as staffing, remuneration, performance evaluation, and training and development. The ultimate goal of HRM is to find and select the best fitting employees, and by appropriate remuneration, training and evaluation mechanisms bring the best out of them.

$\mathrm{HRM}$ is mostly about managing the employees whose most important resource is knowledge, which makes HRM and KM very closely interrelated. HRM and KM share common practices and aims when creating work units, teams, cross-functional cooperation as well as networks inside the organization and across its borders (Svetlik and Stavrou-Costea, 2007).

HRM policy and practice play a significant role in KM and are a powerful means of aligning employee efforts with the knowledge strategy of the firm (Hansen et al., 1999; Hislop, 2003; Scarbrough, 2003; Wong, 2005). Also knowledge governance scholars hold that HRM 
practices are critical antecedents of knowledge processes (Foss and Minbaeva, 2009; Grandori, 2001; Foss, 2007). According to Demarest (1997), modern HRM should be (re-)focused directly to the knowledge-producing capacity of the firm. Scarbrough (2003) states that KM has important implications for the management of human resources, particularly in the development of knowledge sharing.

Scarbrough (2003) pointed out three aspects of HRM that are particularly important in shaping the flow of people and knowledge: employee selection methods, compensation strategies, and career development systems. First, effective selection of new employees is crucial because it is the process of building onto an organization's knowledge and competences. Organizations should hire those who have the required knowledge and skills that they desire. Second, compensation strategies can help promote KM. Both tangible and intangible incentives can motive employees to share and create knowledge. The third aspect is career systems, which concern systematic training and education to employees and how to retain good employees and their knowledge when they leave the organization (Scarbrough, 2003; Wong, 2005).

Based on a review of studies explicitly combining HRM and KM, it seems that an especially essential part of HRM for KM is rewarding and remuneration. For example, Mohrman et al. (2002, p. 149) argue that:

HRM practices, such as development and reward systems, should be directed to motivate and build the capabilities of employees to perform effectively and contribute more extensively to knowledge leverage, generation and application. This will require the redefinition of the employment relationship so that employees see this activity as core to their jobs.

Yahya and Goh (2002) in their empirical study among 300 Malaysian managers found that compensation for knowledge contributions was typical for "knowledge organizations", i.e. Firms with well-functioning knowledge processes.

In the existing literature rewards have mostly been discussed in connection with knowledge sharing. While getting people to share what they know with each other and disseminate this information across the organization has often been hailed as the main focus of KM (e.g. Davenport and Prusak, 1998), several studies have found that knowledge sharing is in fact counter to the automatic behavior of individuals and needs to be especially promoted in order to happen (Szulanski, 1996). Unless knowledge sharing is reflected in reward mechanisms, it is unlikely to take place (Husted and Michailova, 2002; Hansen et al., 1999). Compensation strategies aimed at promoting knowledge sharing can be both tangible (bonuses or one-off rewards) and intangible (status and recognition) (Scarbrough, 2003), monetary or non-monetary (Husted and Michailova, 2002). Incentives of multiple types are likely to lead to best results for encouraging knowledge sharing - as well as other knowledge processes such as knowledge use (Kulkarni et al., 2007).

According to Foss and Minbaeva (2009), while there are some key theoretical contributions arguing the link between HRM, knowledge performance and financial performance, there is a lack of empirical evidence in this field, and consequently, no agreement as to which HRM practices matter for knowledge performance. In fact, empirical research on the importance of HRM for knowledge performance has been mainly based on case studies, and there is a lack of large-N quantitative works on the topic. So there seems to be a similar situation as with ICT practices: while importance of HRM in KM and associated knowledge-based value creation is widely accepted on the anecdotal level, there are few studies empirically ascertaining their relationships (Yahya and Goh, 2002; Oltra, 2005; Prieto-Pastor et al., 2010).

To conclude, HRM practices are a powerful means for stimulating desired knowledge behaviors among employees, and can therefore be expected to contribute to creating competitive advantage and high performance. It therefore is posited that:

H3. The more an organization utilizes HRM practices for managing knowledge, the higher level of competitiveness it reaches.

H4. HRM practices that support KM have a positive impact on economic performance of the firm. 
Finally, it is proposed that the two performance outcomes, competitiveness and financial performance, are interrelated. It is difficult to logically discern the causal direction of these performance indicators. On the one hand it seems plausible that faring better than one's competitors could provide financial benefits for the firm, but then again it seems just as likely that a financially well-off company would have a competitive edge against its competitors. The last hypothesis is therefore formulated as follows:

H5. Competitiveness and financial performance are related with each other.

Based on the argumentation above, the proposed research model can be depicted as follows (see Figure 1).

\section{Research methods}

\subsection{Data collection and sample}

In order to explore the above hypotheses, survey data in three countries - Finland, Russia and China - was collected during February-April 2010. The research was guided by the following considerations in selecting these countries. First, most of the existing empirical papers on knowledge management practices and organizational outcomes are based on data collected from only one single country (e.g. Gloet and Terziovski, 2004; Darroch, 2005; Marqués and Simón, 2006) and thus it is not clear whether their findings apply in other economic and social contexts. Second, all of the above mentioned studies are focused on developed countries, and therefore, there is still very little knowledge about the impact of knowledge management in developing and emerging economies. To bridge these gaps, the authors decided to choose for this study three very different countries: Finland, China and Russia. Finland has been heralded as one of the forerunners in building a sustainable knowledge-based economy and knowledge society, and has recently been either the first or at least in the top three of international competitiveness and educational comparisons. China and Russia are the biggest and growing emerging economies and both have recently put innovation to the forefront of their national development strategy. As knowledge management has the potential to support such strategy, knowledge management has become very relevant in these countries. By analyzing firms in three such different countries, it is possible to obtain a more generalizable picture of the impact of knowledge management on performance than the previous studies, which only have focused on a single country and/or developed countries.

\section{Figure 1 The research model}

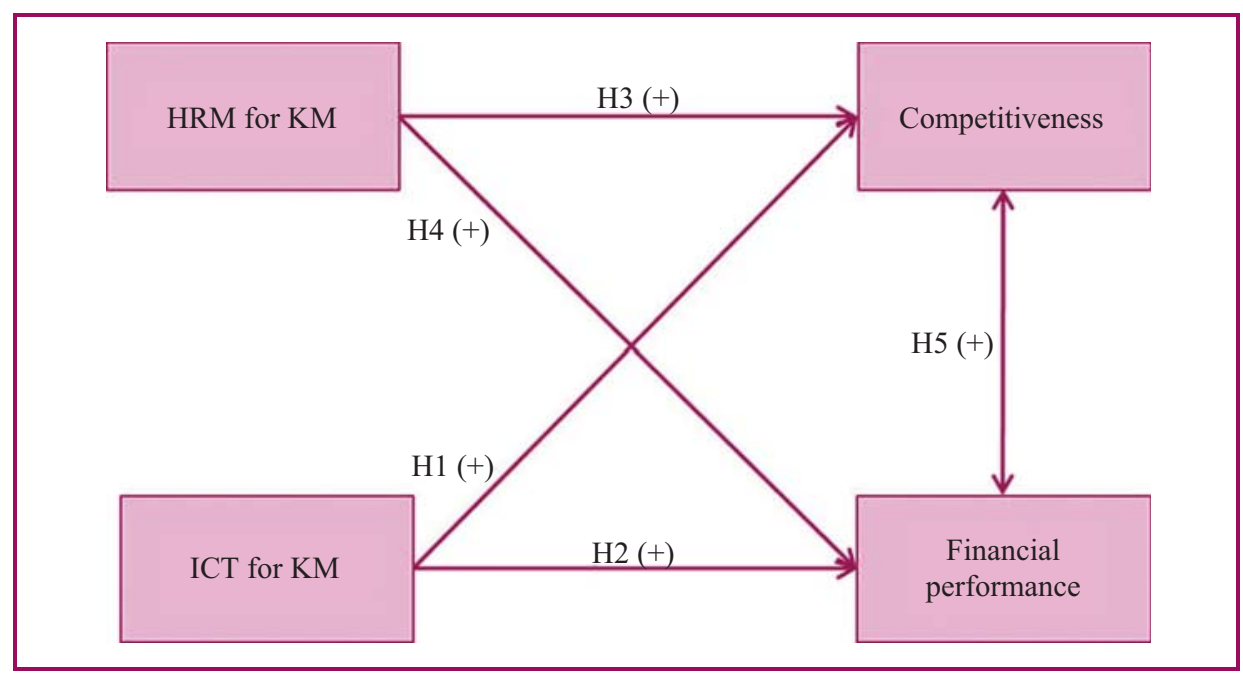

PAGE 624 | JOURNAL OF KNOWLEDGE MANAGEMENT | VOL. 16 NO. 42012 
In order to obtain reliable, diverse and comparable data, it was decided to select companies with 30 or more employees that represent both production and service sectors, and industries with different growth rates.

The survey was run with the usage of the web-based survey software. Therefore, another criterion for selection of the companies into the research pool was added - the company should have a publicly available email address so that the link to the survey could be sent there. The survey has been formulated in a way that any employee of the organization could respond to it, in order to enlarge the potential sample. The administration of the survey proceeded in several stages and differed slightly among three countries due to differences in business culture and attitudes to surveys.

As a first step, the pools of companies that fit into the described above criteria were built based on the publicly available databases. The size of the initial pool was 1,264 for Finland and 10,000 in Russia. These pools differed in size as the different response rate was expected across countries. In China such random pool had not been used, due to the reasons described below.

Next, the invitation letters explaining the purpose and the procedure of the research and providing the link to the web-based questionnaire were emailed to the selected companies. Respondents were promised an executive summary report of the research findings as an incentive to complete the survey. In Finland, this was followed by two e-mail reminders, sent one and two weeks after the initial mail. These resulted in 95 responses, or 7.5 percent response rate, that is a rather good result, taking into account significant length of the survey and absence of any informational support from any industry associations or other industry bodies.

In Russia, acknowledging the typical reluctance in the corporate world to participate in any research due to the culture of the information secrecy, it was decided to have a bigger target random pool of companies. The software that was used for administration of this survey allowed tracking the undelivered emails due to the mistakes in the contact information or due to spam filters. It identified that out of 10,000 contacts selected from databases, only 4064 have actually received the invitation email. This population yielded 145 visits to the survey page (3.6 percent of the population) and 21 responses ( 0.5 percent of the population or 14.5 percent of those who have visited the survey webpage). Taking into account the negative attitudes to survey as the method of data collection in Russia, multiplied by the length of the survey and the novelty of its subject area, this response rate, though being very low, can be considered as good. Further on, to enlarge Russian sample, the invitation to participate in the survey was sent to the members of the alumni club of one of the Russian business schools. This effort yielded a 0.6 percent response rate. In addition, some respondents were also reached through the personal networks of the researchers (with 66 percent response rate). As a result of these efforts, 83 responses were collected.

In China, similarly acknowledging the difficulty of the "cold call" research and importance of personal networking, it was decided to not to use random database mailing. The data collection was supported by Knowledge Management Centre of China (KMC), the biggest online KM community of China, which has about 1,000 members from different industries and regions. Additionally, some respondents were reached through the personal networks of the researchers. As a result of these efforts 83 respondents from China filled this questionnaire. Taken into account specifics of the data collection methods, the response rate via online KM community can be estimated as 5 percent.

As a result of data collection efforts, 261 responses in three countries were collected. A total of 26 responses were excluded from further analyses as they belonged to companies with less than 30 employees or had failed to provide a response on the number of employees in the organization. Therefore, the usable sample consisted of 234 responses, quite evenly representing three countries, with 90 Finnish (38.5 percent), 65 Russian (27.8 percent) and 79 (33.8 percent) Chinese responses, each representing a different company.

The survey reached quite well the management level of the targeted organizations: in Finland and Russia over 65 percent of respondents belonged to middle- or 
top-management, and in China 55 percent. The rest of the surveyed respondents, with minor exceptions held specialist positions in their organizations. While survey questions had been designed in a way that any employee of the organization could answer them, the high share of managerial responses makes the data collected even more insightful. The organizations in the sample represent over 20 industries, with some domination of the manufacturing sector over services (57 percent versus 40 percent, with 3 percent being equally active in both sectors). The majority of the companies employ between 50 and 500 employees (between 60 percent and 70 percent across three countries). Around 70 percent of the companies in each of the three countries are domestically owned.

Taking into account the diversity of the sample that consists of the responses from three very different countries, where different methods have been used to access the organizations in each country, it was necessary to check for the potential differences among the sub-groups in the sample. No major differences in responses among country sub-samples were found thus the sample can be used as a total for further analysis.

\subsection{Measures}

3.2.1 Knowledge management practices. There is a number of measures of knowledge management practices that are reported in the literature (Lee and Choi, 2003; Kulkarni and St Louis, 2003; Darroch, 2005; Zack et al., 2009). However, as knowledge management discipline is still in the development phase, various authors model the knowledge management practices (both their number and their content) somewhat differently and commonly accepted operationalizations of these concepts do not exist. Therefore, for the purposes of this research, and with the presented research model in mind, the scales for HRM and ICT practices for knowledge management were combined by the authors based on the literature, constructing new items where needed.

For all the KM practice items, the respondent was asked to indicate his/her agreement to a particular statement on a six-point Likert scale ( $1=$ strongly disagree, $6=$ strongly agree). Six-point scale was chosen in order to avoid central tendency bias in responses. The initial measures were built in English. In order to ensure that respondents fully understand the questions and to raise the response rate by reaching non-English speaking respondents (Harzing, 2000), the survey items were translated into respective languages of the countries in the sample. To secure measurement equivalence, translation procedure followed several iterations, as recommended in the literature on cross-national research (Brislin, 1970; Singh, 1995).

For information and communication technologies (ICT) scale items from Kulkarni and St Louis (2003), Kruger and Snyman (2007) and Steyn and Kahn (2008) were adopted to examine how organizations used ICT tools and whether the present tools were efficient enough to support their daily work.

Human resource management (HRM) practices scale was compiled based on conceptual considerations from Scarbrough (2003), Storey (2005) and Foss and Michailova (2009). Some items were inspired by Canada Knowledge Management Practices Survey (Statistics Canada, 2001) and other were generated by the research team based on the theoretical considerations from the literature, aiming to identify knowledge management supporting practices across key HRM functions.

Exploratory and confirmatory factor analyses were run to check for the reliability and validity of the developed measurement scales (Hurley et al., 1997). During this analysis, several items from ICT and HRM scales were excluded, resulting in four-item scale for ICT and three-item scale for HRM practices. Table I presents descriptive statistics for resulting latent variables and Table II introduces the items representing variables, factor loadings, internal consistencies and validity indexes of the scales. Confirmatory factor analysis yielded the following goodness of fit statistics: $\chi^{2}=18,246$ with $p=0.148(\geq 0.05), \chi^{2} / \mathrm{df}=1.404(\leq 3)$, $\mathrm{GFI}=0.978(\geq 0.9), \mathrm{AGFI}=0.952(\geq 0.95), \mathrm{TLI}=0.987(\geq 0.95), \mathrm{CFI}=0.992(\geq 0.95)$, RMSEA $=0.042(\leq 0.05)$ with pclose $=0.582(\geq 0.05)$. All of these indexes are within the most conservative limits recommended for each of them (provided in brackets), showing

PAGE 626 | JOURNAL OF KNOWLEDGE MANAGEMENT | VOL. 16 NO. 42012 
Table I Descriptive statistics for knowledge management practices scales

Correlations

\begin{tabular}{llclll}
\hline$\#$ & Latent variable & Mean & SD & 1 & 2 \\
1 & HRM practices for KM & 3.19 & 1.28 & 1 & \\
2 & ICT practices for KM & 4.02 & 1.29 & $0.617^{\star}$ & 1 \\
\multicolumn{2}{l}{ Note: ${ }^{*}$ Correlation is significant on the 0.000 level (two-tailed) } & &
\end{tabular}

Table II Reliability of measurement scales for knowledge management practices

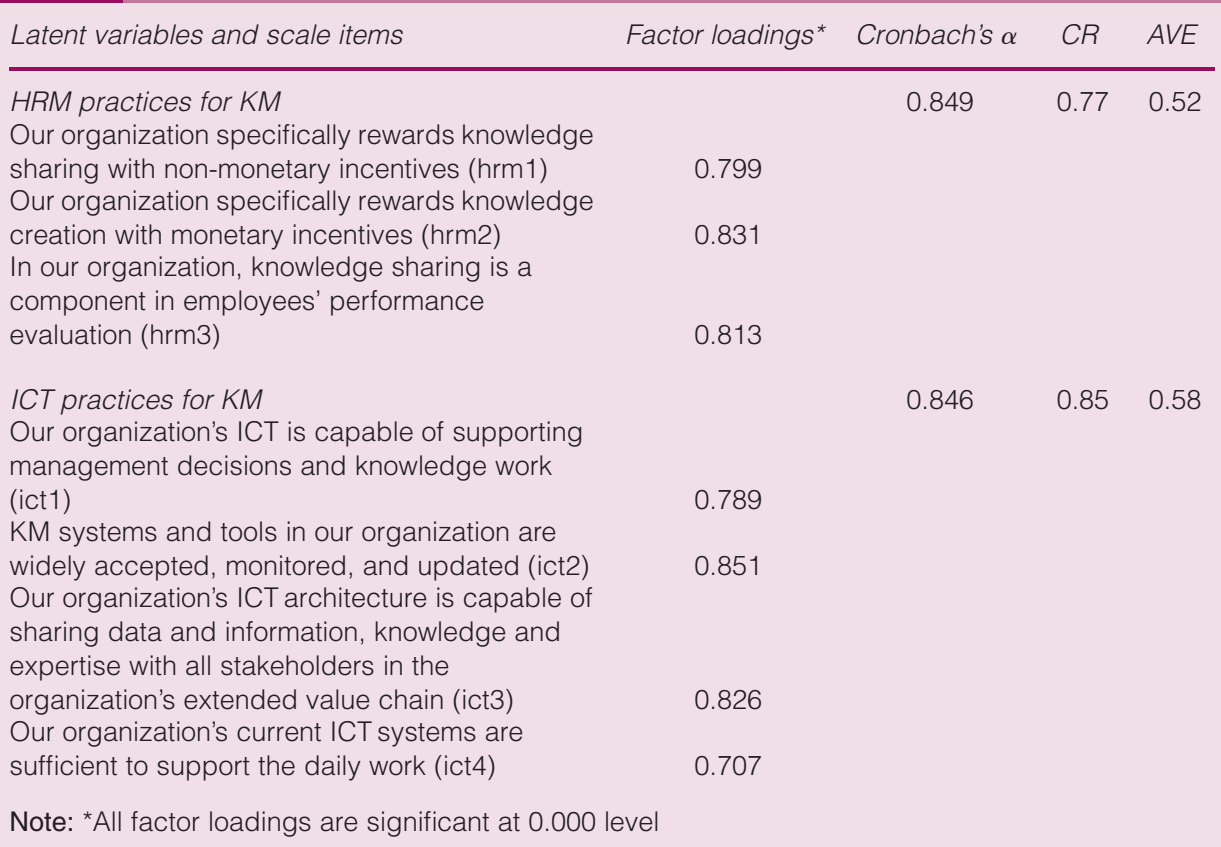

that the measurement model possesses high reliability and a close fit with the observed data.

In addition to Cronbach's $\alpha(\geq 0.7)$, composite validity $(C R ; \geq 0.7)$ and average variance extracted (AVE; $\geq 0.5$ ) indexes (Bagozzi and Yi, 1988) were computed. Table II demonstrates that the scales' parameters fall into the recommended limits. On the top of this, as ICT and HRM constructs are quite strongly correlated (Table I), Fornell and Larcker (1981) criterion was used as an additional check for the discriminant validity. Squared correlation of these variables (0.38) is much lower than AVE of both variables, and, therefore, confirms that the measures chosen represent two distinct variables. To summarize, the analysis suggests that HRM and ICT scales are reliable and possess composite, convergent and discriminant validity.

3.2.2 Organizational performance. Measuring organizational performance is not a trivial task, with different approaches having both advantages and disadvantages (Richard et al., 2009). Taking into account reluctance of Russian and Chinese organizations to share objective performance information perceived measures were opted for. Prior research has demonstrated that perceived measures of performance can be a reasonable substitute for objective measures (Dess and Robinson, 1984) and have a significant correlation with objective measures of financial performance (Hansen and Wernerfelt, 1989).

Another issue considered was the incorporation of external (comparative) and internal views on the performance. Therefore it was decided to use two variables - competitiveness and financial performance. To measure competitiveness, the scale developed and validated by 
Deshpande et al. (1993) and Drew (1997), and later used in knowledge management context by Lee and Choi (2003) was applied. The original scale contains five items and aims to contrast organization's market share, growth, profits, innovativeness and overall success against its competitors (Cronbach's $\alpha=0.8661$ in Lee and Choi, 2003). Results of the analysis of this scale are presented in the Table III. It demonstrates that the scale parameters (Cronbach's $\alpha, \mathrm{CR}$, AVE) fall into the recommended limits. Therefore, the analysis suggests that this scale possesses composite, convergent and discriminant validity.

The measure of financial performance was inspired by Singh et al. (2006) and aimed to evaluate the trend of the main financial indicator of the company's performance - revenues - over the last years. A five-point scale, with scale points being "significantly decreased (more than 15 percent)", "decreased (by less than 15 percent)", "remained stable", "increased (by less than 15 percent)" and "significantly increased (above 15 percent)" was used. The percentage indicators of growth or decline were added in consideration that the perceptions of the growth/decline significance might differ across industries and companies. The rule of the thumb in performance measurement suggests three to five years as a time period for evaluation of such trends. However, as the survey was launched in early 2010, three- or more-years frame would have included the times both before and after the world financial crisis of 2008 and thus might have included very different performance trends. Therefore, the authors have decided to focus on the trend of indicators during and after the crisis (2008-2009). Table IV presents descriptive statistics for the organizational performance scales.

\subsection{Methods of analysis}

As reported above, exploratory and confirmatory factor analysis were performed to check the scales' validity, using SPSS 20.0 and AMOS 20.0 software. In order to examine the impact of HRM and ICT KM practices on organizational performance, structural equation modeling (SEM) was used. The preference for SEM results from two considerations. First, most of the measures in this study are latent variables with multiple indicators. Second, the research design implies multiple simultaneous dependencies among model's variables. SEM appears to be an appropriate technique, as it allows simultaneously testing an integrated set of dependence links, distinguishing between direct and indirect effects, while

Table III Reliability of measurement scale for competitiveness

\begin{tabular}{lcccc}
\hline Latent variables and scale items & Factor loadings ${ }^{\star *}$ & Cronbach's $\alpha$ & CR & AVE \\
\hline Competitiveness & & & & \\
Compared to our key competitors, . . & & 0.849 & 0.77 & 0.52 \\
Our organization is more successful (c1) & 0.853 & & & \\
Our organization has a greater market share (c2) & $-^{*}$ & & & \\
Our organization is growing faster (c3) & 0.806 & & & \\
Our organization is more profitable (c4) & 0.829 & & & \\
Our organization is more innovative (c5) & 0.710 & &
\end{tabular}

Note: ${ }^{*}$ This item was excluded from the original scale based on the confirmatory factor analysis. In Lee and Choi (2003) paper one of the scale items (authors do not report which one) had just above the threshold factor loading of 0.5619 , so our results might be in line with their findings; ${ }^{* *}$ All factor loadings are significant at 0.000 level

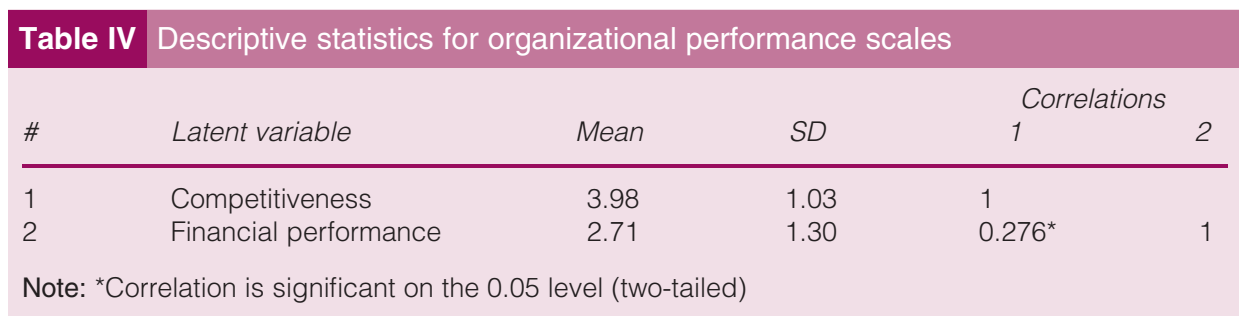


accounting for measurement errors of the multi-item constructs (Anderson and Gerbing, 1988; Bentler, 1980). To test the hypotheses, the maximum likelihood estimation procedure was used, often preferred in management and social sciences studies (Ping, 1996).

\section{Results}

To test the hypotheses, Anderson and Gerbing's (1988) two-step approach was followed. The goal of the first stage - the measurement model - is to obtain an acceptable fit to the data (Anderson and Gerbing, 1988; Bentler, 1980). The scale analysis identified that ICT and HRM practices are strongly correlated, therefore, the link between them was added to the measurement model. As the modeling technique does not give any indication of the direction of the link, and works similarly with the links of both directions, one needs to ground the direction of the link in the theory. Looking at the literature on KM practices, the authors postulated a covariation link between these variables. Also, during this stage one item from the competitiveness scale (c1, see Table III) had to be excluded in order to achieve good model fit.

In the second stage of SEM, the structural model was computed based on the measurement model found in the first stage. The model showed a good fit between the data and the model, having the following goodness of fit statistics: $\chi^{2}=50.361$ with $p=0.105, \chi^{2} / \mathrm{df}=1.291$, $\mathrm{GFI}=0.960, \quad \mathrm{AGFI}=0.933, \quad \mathrm{TLI}=0.982, \quad \mathrm{CFI}=0.987, \quad \mathrm{RMSEA}=0.035 \quad$ with pclose $=0.806$. Only AGFI is a bit lower than the most strict rule of $\geq 0.95$, however, it is still within recommended interval of $\geq 0.9$.

Figure 2 illustrates these findings. Standardized path coefficients are presented above or to the left of the arrows, and squared multiple correlations are presented on the top of the variable.

As Figure 2 demonstrates, both HRM and ICT practices impact competitiveness positively. Therefore, the hypotheses 1 and 3 are confirmed.

Also, both HRM and ICT practices have quite a strong impact on financial performance. However, the impact is very different between the two groups of knowledge management practices - while HRM practices influence financial performance positively with path coefficient of 0.463 , ICT practices influence it negatively, with path coefficient of -0.252 . Therefore, the $\mathrm{H} 4$ is confirmed, while $\mathrm{H} 2$ is rejected.

\section{Figure 2 The structural equation model}

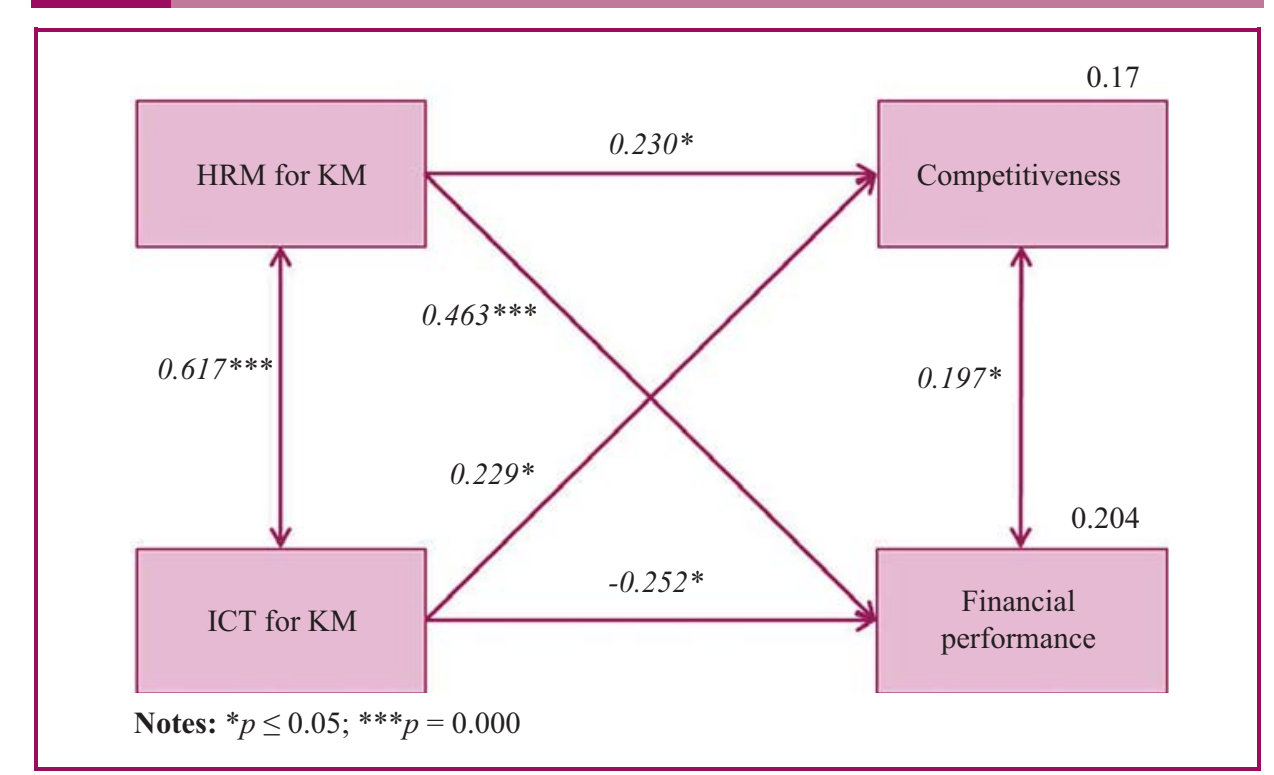

VOL. 16 NO. 42012 |JOURNAL OF KNOWLEDGE MANAGEMENT | PAGE 629 
It was quite surprising to find a negative relationship between ICT practices and financial performance. Therefore tried alternative models were tried, isolating pairs of the variables. None of these models compared to the initial model in terms of explained variance of dependent variables, but they allowed noticing the mediation effect of HRM practices. To test it, total, direct and indirect effects of the variables in the initial model were computed. These findings (standardized effects) are presented in Table V.

Taking into account the postulated link between ICT and HRM as covariance, either one of them could have potentially been a mediator. Table $V$ demonstrates that indirect effects of HRM practices on performance variables are equal to zero (HRM $\rightarrow$ competitiveness) or very small compared with direct effect (HRM $\rightarrow$ Financial performance). Therefore, one can conclude that ICT does not mediate the relationships of HRM to other variables. On the other hand, ICT has a stronger and positive indirect effect on financial performance, compared with the direct and negative effect. Combined, the direct and indirect effects of ICT to financial performance result into a positive total effect. In other words, these results indicate that HRM practices mediate the impact of ICT practices on financial performance, and also change the sign of this impact.

The findings also indicate (see Figure 2) that competitiveness and financial performance are correlated and therefore, $\mathrm{H} 5$ is supported.

Overall, the model explains 17 percent of the variance of competitiveness and 20.4 percent of the variance of financial performance. To examine the total impact of KM practices, a model was ran that comprises KM practices and financial performance only. It has excellent goodness of fit parameters $\left(\chi^{2}=21,973\right.$ with $p=0.233, \chi^{2} / \mathrm{df}=1.221, \mathrm{GFI}=0.976$, $\mathrm{AGFI}=0.952, \mathrm{TLI}=0.991, \mathrm{CFI}=0.994, \mathrm{RMSEA}=0.031$ with pclose $=0.757)$ and shows that together the KM practices explain 17.2 percent of the variance in competitiviness. HRM mediates the impact of ICT to financial performance in a similar way as in the main model presented in Figure 2.

\section{Discussion and conclusions}

This paper examined the impact of the two types of knowledge management practices - in HRM and ICT fields - on company performance. It was found that HRM and ICT practices are quite strongly correlated and have a statistically significant influence on both financial performance and competitiveness. The findings also indicate that HRM practices mediate the impact of ICT on financial performance.

Taking into account that financial performance is influenced by so many other factors besides knowledge management, that are not included in the model, it seems that the obtained results (explanation of 17.2 percent of the variance of financial performance) advocate quite a strong impact of KM practices on performance. This means that KM really does matter to the company bottom line: based on the findings in the international sample of companies in the current study, management of knowledge really functions as an enabler of high performance. Thereby this study confirms the theoretical and case study based arguments about the importance of KM for firm success (e.g. Nonaka and Takeuchi, 1995; Davenport and Prusak, 1998; Edvinsson and Malone, 1997).

Table V Direct and indirect effects in our research model

\begin{tabular}{lcrc} 
Path & Total effect & Direct effect & Indirect effect \\
\hline ICT $\rightarrow$ competitiveness & 0.370 & 0.229 & 0.142 \\
ICT $\rightarrow$ financial performance & 0.107 & -0.252 & 0.358 \\
HRM $\rightarrow$ competitiveness & 0.230 & 0.230 & 0.000 \\
HRM $\rightarrow$ financial performance & 0.508 & 0.463 & 0.050 \\
Competitiveness $\rightarrow$ financial performance & 0.197 & 0.197 & $\mathrm{n} / \mathrm{e}^{*}$ \\
Note: ${ }^{*}$ n/e - no effect & & &
\end{tabular}

PAGE 630 | JOURNAL OF KNOWLEDGE MANAGEMENT | VOL. 16 NO. 42012 
The link between HRM and ICT practices was not initially hypothesized, because the previous literature (e.g. Hansen et al., 1999), suggests that organizations may use these practices independently. However, the findings suggest that organizations quite frequently use both types of knowledge management practices simultaneously. It seems that the findings of the current study may suggest one of the rationales for simultaneous application of these practices.

Indeed, it was found that ICT practices improve financial performance only when they are coupled with HRM practices. When ICT is used alone, it diminishes economic performance. One explanation for this finding might be that while large investments in ICT systems obviously decrease the economic results of a firm, reaping the potential benefits from these investments takes time and requires that employees will actually use the systems (Devaraj and Kohli, 2003). Even more importantly, it is vital to secure that organizational members will use the ICTs for knowledge work processes that benefit the company. As Mohrman et al. (2002, p. 147) put it "it is behaviors, not IT systems, that generate new knowledge, apply it in new settings, embed it in improved processes, yield shared meanings and common knowledge, and underpin the ability of the organization to derive value from knowledge." Thus alone acquiring and implementing an ICT system does not yet mean that people will use it - or in case they do, use it for the benefit of the firm. Therefore it seems that ICTs need to be coupled with the motivational push from HRM remuneration systems in order to get people to really use them for knowledge sharing and creation purposes. In a similar vein, Dedrick et al. (2003) note that to reap full benefits from IT investments, complementary management practices (such as HRM) are needed. Also Gloet and Terziovski (2004) found that KM contributes to innovation performance only when a simultaneous approach of HRM and ICT practices is used. Taken together this speaks for the importance of adopting a socio-technical approach to KM (Pan and Scarbrough, 1998; Meso and Smith, 2000; Bhatt, 2001).

Interestingly, some information systems studies argue for the opposite relationship between ICT and HRM, suggesting that information technology enables overcoming some of the limitations of human-intensive mechanisms related with restricted information processing (Grant, 1996) and coordination capabilities (Tanriverdi, 2005). However, contrary to these studies, a mediation effect of ICT to HRM-performance links was not found.

To conclude, this paper contributed to the literature on knowledge-based organizing by empirically analyzing the performance impact of various areas of $\mathrm{KM}$ and extended understanding on the knowledge-based view of the firm by examining how KM is related with various organizational outcomes. By explicitly addressing two of the main formal mechanisms of knowledge management, ICT and HRM-related practices, this paper also responded to the research gap noted by Foss and colleagues (Foss, 2007; Foss et al., 2010) on the dismissal of knowledge governance and the formal aspects of organizing for knowledge.

For the practicing managers this research shows that KM really matters to the company bottom line by significantly increasing financial performance of the firm. It further demonstrates that rather than (only) ephemeral management philosophy and rhetoric, knowledge management is about very concrete and systematic management activities related with providing appropriate ICT systems to help with knowledge work processes and aligning HRM incentives to empower and motivate people to share, create and apply what they know. If these two are combined, tangible financial benefits are likely to follow. An important lesson from research is that coupling ICT practices for KM with HRM practices for $\mathrm{KM}$ is not just desirable but critical for organizational bottom-line.

One limitation of this study is that only cross-sectional data was collected. Devaraj and Kohli (2003) found that the payoff from IT may not be realized instantaneously but only after certain periods of time. Therefore it might be that had performance data been acquired at a later point in time, the results might have demonstrated a direct impact between ICT and performance. It also would have been preferable to obtain information on the financial performance from external objective sources. 
Another limitation is linked to the cross-national nature of the sample and the sizes of country sub-samples. The countries addressed in this research are united by being peripheral to mainstream knowledge management research, but they are still quite different in their general management practices (e.g. Fey et al., 2004, 2006) so it might be expected that KM practices may have different impacts on organizational performance. However, the amount of observations from each country in the current dataset was not sufficient for testing the research model separately for each country. Significant differences in response distributions across countries were not found and thus the total sample was used for the analysis; however, this lack of the differences might be also linked to the sizes of sub-samples. Therefore, further tests of the proposed model with bigger country samples might yield interesting comparative results.

One more limitation refers to the chosen method of analysis. Though SEM allows assessing a web of relationships and thus was very appropriate for this study, it also has some limitations (Brannick, 1995; Shool et al., 2004). With the samples $\leq 250$ (as used in this study) it may over-reject true models (Bentler and Yuan, 1999; Fan et al., 1999), leading the researchers to exclude some items from the model, as happened in this case. Therefore, further examination of the proposed research model with full presented scales in a bigger sample may be important. Another limitation of this paper is that it did not address knowledge processes (such as knowledge creation, sharing, transfer and application). It can be argued (cf. Demarest, 1997) that knowledge processes - knowledge creation, sharing, application etc. - as fundamental human activities happen to some extent in any organization, regardless of whether they are consciously managed or not. While addressing the conscious managerial activities by which the effectiveness and efficiency of organizational knowledge management is established, i.e. KM practices, this paper ignored knowledge processes. However, it might be that $\mathrm{KM}$ activities in fact impact performance through promoting and accelerating knowledge processes. Therefore further examination into the links between KM practices, knowledge processes and organizational outcomes certainly represent a worthwhile avenue for future research.

\section{References}

Adams, G.L. and Lamont, B.T. (2003), "Knowledge management systems and developing sustainable competitive advantage", Journal of Knowledge Management, Vol. 7 No. 2, pp. 142-54.

Alavi, M. and Leidner, D.E. (2001), "Review: knowledge management and knowledge management systems: conceptual foundations and research issues", MIS Quarterly, Vol. 25 No. 1, pp. 107-36.

Anderson, J.C. and Gerbing, D.W. (1988), "Structural equation modeling in practice: a review and recommended two-step approach", Psychological Bulletin, Vol. 103 No. 3, pp. 411-23.

Andreeva, T. and Kianto, A. (2011), "Knowledge processes, knowledge-intensity and innovation: a moderated mediation analysis", Journal of Knowledge Management, Vol. 15 No. 6, pp. 1016-34.

Bagozzi, R.P. and Yi, Y. (1988), "On the evaluation of structural equation models", Journal of the Academy of Marketing Science, Vol. 16 No. 1, pp. 74-94.

Barney, J. (1991), "Firm resources and sustained competitive advantage", Journal of Management, Vol. 17 No. 1, pp. 99-120.

Barua, A., Kriebel, C. and Mukhopadhyay, T. (1995), "Information technologies and business value: an analytic and empirical investigation", Information Systems Research, Vol. 6 No. 1, pp. 3-23.

Bentler, P.M. (1980), "Multivariate analysis with latent variables: causal modeling", in Rozenweig, M.R. and Porter, L.W. (Eds), Annual Review of Psychology, Vol. 31, Annual Reviews, Palo Alto, CA, pp. 419-56.

Bentler, P.M. and Yuan, K. (1999), "Structural equation modeling with small samples: test statistics", Multivariate Behavioral Research, Vol. 34 No. 2, pp. 181-97.

Bhatt, G. (2001), "Knowledge management in organizations: examining the interaction between technologies, techniques, and people", Journal of Knowledge Management, Vol. 5 No. 1, pp. 68-75.

Brannick, M.T. (1995), "Critical comments on applying covariance structure modelling", Journal of Organizational Behavior, Vol. 16 No. 3, pp. 201-13. 
Brislin, R. (1970), "Back translation for cross-cultural research", Journal of Cross Cultural Psychology, Vol. 1 No. 3, pp. 185-216

Brynjolfsson, E. and Hitt, L. (1996), "Paradox lost? Firm-level evidence on the returns to information systems spending", Management Science, Vol. 42 No. 4, pp. 541-58.

Carneiro, A. (2000), "How does knowledge management influence innovation and competitiveness?", Journal of Knowledge Management, Vol. 4 No. 2, pp. 87-98.

Chapman, R. and Magnusson, M. (2006), "Continuous innovation, performance and knowledge management: an introduction", Knowledge and Process Management, Vol. 13 No. 3, pp. 129-31.

Chuang, S.-H. (2004), "A resource-based perspective on knowledge management capability and competitive advantage: an empirical investigation", Expert Systems with Applications, Vol. 27 No. 3, pp. 459-65.

Darroch, J. (2005), "Knowledge management, innovation and firm performance", Journal of Knowledge Management, Vol. 9 No. 3, pp. 101-15.

Darroch, J. and McNaughton, R. (2003), "Beyond market orientation. Knowledge management and the innovativeness of New Zealand firms", European Journal of Marketing, Vol. 37 Nos 3/4, pp. 572-93.

Davenport, T. and Prusak, L. (1998), Working Knowledge: How Organizations Manage What They Know, Harvard Business School Press, Boston, MA.

Davenport, T., De Long, D. and Beers, M. (1998), "Successful knowledge management projects", Sloan Management Review, Vol. 39 No. 2, pp. 43-57.

Dedrick, J., Gurbaxani, V. and Kraemer, K. (2003), "Information technology and economic performance: a critical review of the empirical evidence", ACM Computing Surveys, Vol. 35 No. 1, pp. 1-28.

Demarest, M. (1997), "Understanding knowledge management", Long Range Planning, Vol. 30 No. 3, pp. 374-84.

Deshpande, R., Jarley, U. and Webster, F. (1993), "Corporate culture, customer orientation, and innovativeness in Japanese firms: a quadrad analysis", Journal of Marketing, Vol. 57 No. 1, pp. 23-37.

Dess, G.G. and Robinson, R.B. Jr (1984), "Measuring organizational performance in the absence of objective measures: the case of the privately-held firm and conglomerate business unit", Strategic Management Journal, Vol. 5 No. 3, pp. 265-73.

Devaraj, S. and Kohli, R. (2003), "Performance impacts of information technology: is actual usage the missing link?", Management Science, Vol. 49 No. 3, pp. 273-89.

Drew, S. (1997), "From knowledge to action: the impact of benchmarking on organizational performance", Long Range Planning, Vol. 30 No. 3, pp. 427-41.

Edvinsson, L. and Malone, M. (1997), Intellectual Capital: Realising Your Company's True Value by Finding Its Hidden Brainpower, Harper Collins, New York, NY.

Fan, X., Thompson, B. and Wang, L. (1999), "Effects of sample size, estimation methods, and model specification on structural equation", Structural Equation Modeling, Vol. 6 No. 1, pp. 56-83.

Fey, C.F., de Koning, A. and Delios, A. (2006), "How similar is the world in the internet era? A comparison of e-business in China, Russia, and Sweden", Thunderbird International Business Review, Vol. 48 No. 5 , pp. 727-47.

Fey, C.F., Pavlovskaya, A. and Tang, J. (2004), "Does one shoe fit everyone? A comparison of human resource management in China, Russia, and Finland", Organization Dynamics, Vol. 33 No. 1, pp. 79-97.

Foot, M. and Hook, C. (2008), Introducing Human Resource Management, 5th ed., Financial Times/Prentice Hall, Harlow.

Fornell, C. and Larcker, D. (1981), "Evaluating structural equation models with unobservable variables and measurement error", Journal of Marketing Research, Vol. 18 No. 1, pp. 39-50.

Foss, N. (2007), "The emerging knowledge governance approach: challenges and characteristics", Organization, Vol. 14 No. 1, pp. 29-52.

Foss, N. and Michailova, S. (eds.) (2009), Knowledge Governance: Processes and Perspectives, Oxford University Press, Oxford. 
Foss, N. and Minbaeva, D. (2009), "Governing knowledge: the strategic human resource management dimension”, SWG working papers, 3/2009, Copenhagen Business School, Copenhagen.

Foss, N., Husted, K. and Michailova, S. (2010), "Governing knowledge sharing in organizations: levels of analysis, governance mechanisms and research directions", Journal of Management Studies, Vol. 47 No. 3, pp. 455-82.

Gloet, M. and Terziovski, M. (2004), "Exploring the relationship between knowledge management practices and innovation performance", Journal of Manufacturing Technology Management, Vol. 15 No. 5 , pp. 402-9

Gold, A., Malhotra, A. and Segard, A. (2001), "Knowledge management: an organizational capabilities perspective", Journal of Management Information Systems, Vol. 18 No. 1, pp. 185-214.

Grandori, A. (2001), "Neither hierarchy nor identity: knowledge-governance mechanisms and the theory of the firm", Journal of Management and Governance, Vol. 5 Nos 3/4, pp. 381-99.

Grant, R. (1996), "Toward a knowledge-based theory of the firm", Strategic Management Journal, Vol. 17, Winter, pp. 109-22.

Grant, R. and Spender, J.-C. (1996), "Knowledge and the firm: an overview", Strategic Management Journal, Vol. 17, Winter, pp. 3-9.

Hansen, G.S. and Wernerfelt, B. (1989), "Determinants of firm performance: the relative importance of economic and organizational factors", Strategic Management Journal, Vol. 10 No. 5, pp. 399-411.

Hansen, M.T., Nohria, N. and Tierney, T. (1999), "What's your strategy for managing knowledge?", Harvard Business Review, Vol. 77 No. 2, pp. 106-16.

Harzing, A. (2000), "Cross-national industrial mail surveys: why do response rates differ between countries?", Industrial Marketing Management, Vol. 29 No. 3, pp. 243-54.

Hasanali, F. (2002), "Critical success factors of knowledge management", available at: http://polaris. umuc.edu/mts/TMAN/TMAN_636/articles/csfs.pdf (accessed 27 March 2012).

Hislop, D. (2003), "Linking human resource management and knowledge management view commitment: a review and research agenda", Employee Relations, Vol. 25 No. 2, pp. 182-202.

Hurley, A.E., Scandura, T.A., Schriesheim, C.A., Brannick, M.T., Seers, A., Vandeberg, R.J. and Williams, L.J. (1997), "Exploratory and confirmatory factor analysis: guidelines, issues, and alternatives", Journal of Organizational Behavior, Vol. 18 No. 6, pp. 667-83.

Husted, K. and Michailova, S. (2002), "Diagnosing and fighting knowledge-sharing hostility", Organizational Dynamics, Vol. 31 No. 1, pp. 60-73.

Kianto, A. (2011), "The influence of knowledge management on continuous innovation", International Journal of Technology Management, Vol. 55 Nos 1/2, pp. 110-21.

Kiessling, T.S., Richey, R.G., Meng, J. and Dabic, M. (2009), "Exploring knowledge management to organizational performance outcomes in a transitional economy", Journal of World Business, Vol. 44 No. 4, pp. 421-33.

Kogut, B. and Zander, U. (1992), "Knowledge of the firm, combinative capabilities, and the replication of technology", Organization Science, Vol. 3 No. 3, pp. 383-97.

Kohli, R. and Devaraj, S. (2003), "Measuring information technology payoff: a meta-analysis of structural variables in firm-level empirical research", Information Systems Research, Vol. 14 No. 2, pp. 127-45.

Kruger, C.J. and Snyman, M.M.M. (2007), "Guidelines for assessing the knowledge management maturity of organizations", South African Journal of Information Management, Vol. 9 No. 3, pp. 1-11.

Kulkarni, U. and St Louis, R. (2003), "Organizational self assessment of knowledge management maturity", Proceedings of 9th Americas Conference on Information Systems (AMCIS), August 4-6, Tampa, USA.

Kulkarni, U., Ravindran, S. and Freeze, R. (2007), "A knowledge management success model: theoretical development and empirical validation", Journal of Management Information Systems, Vol. 23 No. 3, pp. 309-47. 
Lee, H. and Choi, B. (2003), "Knowledge management enablers, processes, and organizational performance: an integrative view and empirical examination", Journal of Management Information Systems, Vol. 20 No. 1, pp. 179-228.

Marqués, D. and Simón, F. (2006), "The effect of knowledge management practices on firm performance", Journal of Knowledge Management, Vol. 10 No. 3, pp. 143-56.

Meso, P. and Smith, R. (2000), "A resource-based view of organizational knowledge management systems", Journal of Knowledge Management, Vol. 4 No. 3, pp. 224-34.

Mohrman, S., Finegold, D. and Klein, J. (2002), "Designing the knowledge enterprise: beyond programs and tools", Organizational Dynamics, Vol. 31 No. 2, pp. 134-50.

Nonaka, I. and Takeuchi, H. (1995), The Knowledge-creating Company, Oxford University Press, New York, NY.

Oltra, V. (2005), "Knowledge management effectiveness factors: the role of HRM", Journal of Knowledge Management, Vol. 9 No. 4, pp. 70-86.

Pan, S. and Scarbrough, H. (1998), "A socio-technical view of knowledge-sharing at Buckman Laboratories", Journal of Knowledge Management, Vol. 2 No. 1, pp. 55-66.

Penrose, E. (1959), The Theory of the Growth of the Firm, Oxford University Press, Oxford.

Ping, R.A. Jr (1996), "Estimating latent variable interactions and quadratics: the state of this art", Journal of Management, Vol. 22 No. 1, pp. 163-83.

Prieto-Pastor, I., Pérez Santana, M. and Martín Sierra, C. (2010), "Managing knowledge through human resource practices: empirical examination on the Spanish automotive industry", The International Journal of Human Resource Management, Vol. 21 No. 13, pp. 2452-67.

Richard, P.J., Devinney, T.M., Yip, G.S. and Johnson, G. (2009), "Measuring organizational performance: towards methodological best practice", Journal of Management, Vol. 35 No. 3, pp. 718-804.

Scarbrough, H. (2003), "Knowledge management, HRM and the innovation process", International Journal of Manpower, Vol. 24 No. 5, pp. 501-16.

Shool, C.L., Ketchen, D.J., Jult, G.T.M. and Kacmar, K.M. (2004), "An assessment of the use of structural equation modeling in strategic management research", Strategic Management Journal, Vol. 25 No. 4, pp. 397-404

Singh, J. (1995), "Measurement issues in cross-national research", Journal of International Business Studies, Vol. 26 No. 3, pp. 597-620.

Singh, M.D., Shankar, R., Narain, R. and Kumar, A. (2006), "Survey of knowledge management practices in Indian manufacturing industries", Journal of Knowledge Management, Vol. 10 No. 6, pp. 110-28.

Spender, J.-C. (1996), "Organizational knowledge, learning and memory: three concepts in search of a theory", Journal of Organizational Change, Vol. 9 No. 1, pp. 63-78.

Statistics Canada (2001), "Knowledge management in practice in Canada", Science, Innovation and Electronic Information Division, Statistics Canada, available at: www.statcan.gc.ca/pub/88f0006x/ 88f0006x2003007-eng.pdf (accessed 27 March 2012).

Steyn, C. and Kahn, M. (2008), "Towards the development of a knowledge management practices survey for application in knowledge intensive organisations", South African Journal of Business Management, Vol. 39 No. 1, pp. 45-53.

Storey, J. (2005), "Human resource policies for knowledge work", in Ray, T., Quintas, P. and Little, S. (Eds), Managing Knowledge: An Essential Reader, Sage, London.

Svetlik, I. and Stavrou-Costea, E. (2007), "Connecting human resources management and knowledge management", International Journal of Manpower, Vol. 28 No. 3, pp. 197-206.

Szulanski, G. (1996), "Exploring internal stickiness: impediments to the transfer of best practice within the firm", Strategic Management Journal, Vol. 17, Winter, pp. 27-43.

Tanriverdi, H. (2005), "Information technology relatedness, knowledge management capability, and performance of multibusiness firms", MIS Quarterly, Vol. 29 No. 2, pp. 311-34. 
Von Krogh, G. (1998), "Care in knowledge creation", California Management Review, Vol. 40 No. 3, pp. 133-53.

Wong, K.Y. (2005), "Critical success factors for implementing knowledge management in small and medium enterprises", Industrial Management \& Data Systems, Vol. 105 No. 3, pp. 261-79.

Yahya, S. and Goh, W.-K. (2002), "Managing human resources toward achieving knowledge management", Journal of Knowledge Management, Vol. 6 No. 5, pp. 457-68.

Zack, M., McKeen, J. and Singh, S. (2009), "Knowledge management and organizational performance: an exploratory survey", Journal of Knowledge Management, Vol. 13 No. 6, pp. 392-409.

Zaim, H., Tatoglu, E. and Zaim, S. (2007), "Performance of knowledge management practices: a causal analysis", Journal of Knowledge Management, Vol. 11 No. 6, pp. 54-67.

Zuboff, S. (1988), In the Age of the Smart Machine: The Future of Work and Power, Basic Books, New York, NY.

\section{About the authors}

Tatiana Andreeva is an Associate Professor at the Organizational Behavior and Human Resource Management Department, St Petersburg University Graduate School of Management, Russia. Her teaching and research are focused on knowledge management, change management, and cross-cultural issues in management. Her current research interests include strategic knowledge management and micro-foundations of knowledge management. She has authored and co-authored several academic articles, papers, and book chapters related to these issues. Prior to joining academia, she worked in management consulting in the area of strategy, organizational development and knowledge management.

Aino Kianto is a Professor of Knowledge Management in the School of Business at Lappeenranta University of Technology, Finland. Her teaching and research focus on knowledge management, intellectual capital, creativity, innovation and organizational renewal. Her current interests include the knowledge-based view of the firm and measurement of knowledge-related phenomena in organizations. She has authored and co-authored several academic articles, papers, books and book chapters related to knowledge management, intellectual capital and innovation. In addition to academia, she also has worked with the Future committee of the Finnish parliament and regularly lectures for companies. Aino Kianto is the corresponding author and can be contacted at: aino.kianto@lut.fi

To purchase reprints of this article please e-mail: reprints@emeraldinsight.com Or visit our web site for further details: www.emeraldinsight.com/reprints 
This article has been cited by:

1. Abu Hassan Abu Bakar, Mohamad Nizam Yusof, Muhammad Asim Tufail, Wiwied Virgiyanti. 2016. Effect of knowledge management on growth performance in construction industry. Management Decision 54:3. . [Abstract] [PDF]

2. Tatiana Andreeva, Tatiana Garanina. 2016. Do all elements of intellectual capital matter for organizational performance? Evidence from Russian context. Journal of Intellectual Capital 17:2. . [Abstract] [PDF]

3. Henri Tapio Inkinen. 2016. Review of empirical research on knowledge management practices and firm performance. Journal of Knowledge Management 20:2. . [Abstract] [PDF]

4. Sharmila Jayasingam, Muhiniswari Govindasamy, Sharan Kaur Garib Singh. 2016. Instilling affective commitment: insights on what makes knowledge workers want to stay. Management Research Review 39:3, 266-288. [Abstract] [Full Text] [PDF]

5. Mei-Hsiang Wang, Tarng-Yao Yang. 2016. Investigating the success of knowledge management: An empirical study of smalland medium-sized enterprises. Asia Pacific Management Review . [CrossRef]

6. Hsiu-Fen Lin. 2015. Linking knowledge management orientation to balanced scorecard outcomes. Journal of Knowledge Management 19:6, 1224-1249. [Abstract] [Full Text] [PDF]

7. Henri Tapio Inkinen, Aino Kianto, Mika Vanhala. 2015. Knowledge management practices and innovation performance in Finland. Baltic Journal of Management 10:4, 432-455. [Abstract] [Full Text] [PDF]

8. Pooja Kushwaha, M.K. Rao. 2015. Integrative role of KM infrastructure and KM strategy to enhance individual competence. VINE 45:3, 376-396. [Abstract] [Full Text] [PDF]

9. Harold M. Schroeder. 2015. Knowledge, learning and development for success in the new business environment: an art and science approach. Development and Learning in Organizations: An International Journal 29:5, 10-12. [Abstract] [Full Text] [PDF]

10. Henri Inkinen. 2015. Review of empirical research on intellectual capital and firm performance. Journal of Intellectual Capital 16:3, 518-565. [Abstract] [Full Text] [PDF]

11. Kyeonghee Jang. 2015. Technology Could Be Harmful Rather Than Beneficial: An Empirical Investigation of Caseworkers' Perceptions Using a Knowledge Management Framework. Journal of Social Service Research 41, 246-268. [CrossRef]

12. Jason F. Cohen, Karen Olsen. 2015. Knowledge management capabilities and firm performance: A test of universalistic, contingency and complementarity perspectives. Expert Systems with Applications 42, 1178-1188. [CrossRef]

13. Rafi Ashrafi, John Mueller. 2015. Delineating IT Resources and Capabilities to Obtain Competitive Advantage and Improve Firm Performance. Information Systems Management 32, 15-38. [CrossRef]

14. Luís Valentim, João Veríssimo Lisboa, Mário Franco. 2015. Knowledge management practices and absorptive capacity in small and medium-sized enterprises: is there really a linkage?. R\&D Management n/a-n/a. [CrossRef]

15. Anna-Maija Nisula, Aino Kianto. 2015. The role of knowledge management practices in supporting employee capacity for improvisation. The International Journal of Human Resource Management 1. [CrossRef]

16. Christian Maurer, Markus Steiner, Reinhard Bernsteiner. 2015. How to Improve Information and Knowledge Quality for Business Benefits. Journal of Economics, Business and Management 3, 780-786. [CrossRef]

17. Peter Massingham. 2014. An evaluation of knowledge management tools: Part 2 - managing knowledge flows and enablers. Journal of Knowledge Management 18:6, 1101-1126. [Abstract] [Full Text] [PDF]

18. Peter Massingham. 2014. An evaluation of knowledge management tools: Part 1 - managing knowledge resources. Journal of Knowledge Management 18:6, 1075-1100. [Abstract] [Full Text] [PDF]

19. Alison J. Glaister, Yipeng Liu, Sunil Sahadev, Emanuel Gomes. 2014. Externalizing, Internalizing and Fostering Commitment: The Case of Born-Global Firms in Emerging Economies. Management International Review 54, 473-496. [CrossRef]

20. Aino Kianto, Paavo Ritala, John-Christopher Spender, Mika Vanhala. 2014. The interaction of intellectual capital assets and knowledge management practices in organizational value creation. Journal of Intellectual Capital 15:3, 362-375. [Abstract] [Full Text] [PDF]

21. Silvia Martelo-Landroguez, Juan-Gabriel Cegarra-Navarro. 2014. Linking knowledge corridors to customer value through knowledge processes. Journal of Knowledge Management 18:2, 342-365. [Abstract] [Full Text] [PDF]

22. Mahdavi Mazdeh Mohammad, Hesamamiri Roozbeh. 2014. Knowledge management reliability and its impact on organizational performance. Program 48:2, 102-126. [Abstract] [Full Text] [PDF]

23. Hsiu-Fen Lin. 2014. A multi-stage analysis of antecedents and consequences of knowledge management evolution. Journal of Knowledge Management 18:1, 52-74. [Abstract] [Full Text] [PDF] 
24. Gulzhanat Tayauova, Diana Amirbekova, Almagul Kanagatova. 2014. Development of Corporate Knowledge Management: A Case of Educational Sphere. Procedia - Social and Bebavioral Sciences 116, 4449-4451. [CrossRef]

25. L. Statsenko, L. Bozhko, G. Prause, V. Ireland. 2013. Critical issues of intellectual capital theory in transitional countries. Global Business Perspectives 1, 515-537. [CrossRef]

26. Alexander Serenko, Nick Bontis. 2013. Investigating the current state and impact of the intellectual capital academic discipline. Journal of Intellectual Capital 14:4, 476-500. [Abstract] [Full Text] [PDF]

27. Mohamed A.F. Ragab, Amr Arisha. 2013. Knowledge management and measurement: a critical review. Journal of Knowledge Management 17:6, 873-901. [Abstract] [Full Text] [PDF]

28. M.N. Ravishankar, Shan L. Pan. 2013. Examining the influence of modularity and knowledge management (KM) on dynamic capabilities: Insights from a call center. International Journal of Information Management 33, 147-159. [CrossRef]

29. Rawan Khasawneh, Ameen AlazzamCustomer Knowledge Management (CKM): 1-15. [CrossRef] 